\title{
NARRATIVAS E REPRESENTAÇÕES DE UM PERCURSO EDUCACIONAL E DE UM IDEÁRIO EDUCATIVO ESTRANGEIRO NAS CARTAS DE UMA EDUCADORA
}

\author{
Silmara de Fatima Cardoso ${ }^{1}$
}

USP

\section{RESUMO}

$\mathrm{O}$ que as cartas de uma educadora enviadas a um amigo podem revelar sobre o seu percurso educacional, bem como o seu olhar sobre um modelo de educação estrangeiro considerado ideal? Essa questão é fio condutor do presente texto, que tem por objetivo analisar a correspondência de Ignácia Guimarães durante e após a sua viagem à Europa enviada a Anísio Teixeira. Das cartas analisadas somam-se 12, de 37 folhas no total, do período de 1929 a 1933. Essas cartas estão localizada no arquivo pessoal de Anísio Teixeira sob a guarda do CPDOC - Centro de Pesquisa e Documentação de História Contemporânea da Fundação Getúlio Vargas no Rio de Janeiro. Algumas foram escritas em papel timbrado e apresentam marcas de um português da época. Muitas palavras estão ilegíveis ou rasuradas. Entre os assuntos que se destacam estão os relatos acerca da viagem de Ignácia Guimarães a Europa; condições da educação e das escolas alemãs, a sua atuação enquanto educadora, questões de sua vida pessoal, profissional e a atuação de Anísio Teixeira enquanto administrador do Ensino Público na antiga Capital Federal, Rio de Janeiro. Essa correspondência se mostra uma preciosa fonte de estudo, pois traz descrito mesmo que seja do ponto de vista da remetente Ignácia Guimarães a representação de sua atuação no campo educacional e de determinado modelo de educação valorizado naquele momento e que estava a se impor, circulando em esfera nacional e internacional. Apesar de terem sido produzidas na esfera da intimidade e sem intenção de publicação, as cartas enviadas a Anísio Teixeira esboçam um desejo de comunicação. Ignácia Guimarães escreveu a respeito de coisas sobre as quais gostariam de falar, de refletir, questionar, primeiramente para "si" e depois para o "outro".

Palavras-chave: correspondência pessoal; representações de si; ideário educacional; Anísio Teixeira

\section{NARRATIVES AND REPRESENTATIONS OF AN EDUCATIONAL COURSE AND A FOREIGN EDUCATIONAL IDEAS IN THE LETTERS OF AN EDUCATOR}

\begin{abstract}
What do the letters of a teacher sent a friend can reveal about your educational path, as well as your look on a model for education foreign considered ideal? This issue is common thread of this text, which aims to analyze the correspondence of Ignacia Guimarães during and after your trip to Europe sent to Anísio Teixeira. Analyzed the letters add up to 12, 37 sheets in total, for the period 1929-1933. These cards are located in the personnel file Anísio Teixeira in the custody of CPDOC - Center for Research and Documentation of Contemporary History at the Getulio Vargas foundation in Rio de Janeiro. Some were written on letterhead and show the marks of a Portuguese of the time. Many words are illegible or tampered. Among the issues that stand out are the trip reports about Ignacia Guimarães Europe trip; conditions of education and German schools, while teacher its performance, issues his personal life and professional activities of Anísio Teixeira as
\end{abstract}


administrator in Public Education of old former Federal Capital, Rio de Janeiro. This correspondence proves a valuable source of study, as it brings described - even from the point of view of the sender Ignacia Guimarães representation of their work in the educational field and a given model of education valued at that time and that was to prevail, circulating at national and international level. Although they have been produced in the sphere of intimacy and with no intention of publication, the letters sent to Anísio Teixeira design a desire to communicate. Ignacia Guimaraes wrote about things which they would like to talk, reflect, question, first to "you" and then the "other.

Keywords: personal correspondence; representations of self; educational ideal; Anísio Teixeira

O que as cartas de uma educadora enviadas a um amigo podem revelar sobre o seu percurso educacional, bem como o seu olhar sobre um modelo de educação estrangeiro considerado ideal? Essa questão é fio condutor do presente texto, que tem por objetivo analisar a correspondência de Ignácia Guimarães durante e após a sua viagem à Europa enviada a Anísio Teixeira.

Escrever atende necessidades específicas e múltiplas: aproveitar a experiência na sua totalidade, deixar um documento original, que seja útil para outros, guardar melhor as imagens e impressões colhidas ou transmitir acontecimentos e fatos. $\mathrm{O}$ ato de registrar é importante, pois permite construir uma memória compreensiva; aquela que não é simples recordação, mas a base para reflexão.

De acordo com Mignot (2003) aprisionar no papel o banal ou o surpreendente da vida cotidiana tem contagiado a muitos sujeitos de diferentes gerações sejam homens, mulheres, adolescentes, jovens, adultos ou velhos. A escrita diária acontece por muitos motivos e razões diferenciadas.

Apesar de terem sido produzidas na esfera da intimidade e sem intenção de publicação, as cartas enviadas a Anísio Teixeira esboçam um desejo de comunicação. Ignácia Guimarães escreveu a respeito de coisas sobre as quais gostariam de falar, de refletir, questionar, primeiramente para "si" e depois para o "outro".

É necessário analisar as narrativas da correspondência de Ignácia Guimarães, levando em consideração que foram produzidas por um sujeito histórico - cuja formação, intenção, visão de mundo e objetivo podem influir decisivamente na tecitura dos seus textos.

Conforme Gomes (2004, p. 14) a escrita pessoal assume a subjetividade de seu autor como dimensão integrante de sua linguagem, construindo sobre ela "a sua verdade". Dessa forma, torna-se necessário ao pesquisador atentar para a ótica assumida pelo registro em como seu autor a expressa. Isto é, "o documento não trata de "dizer o que houve", mas de dizer o que o autor diz que viu, sentiu e experimentou, retrospectivamente, em relação a um acontecimento". É nesse sentido que importa analisar as correspondências de Ignácia Guimarães, o que ela viu, sentiu e experimentou, enfim, o que considerava importante registrar.

Gomes nos alerta a compreender a escrita pessoal não como uma verdade a ser revelada por quem a escreveu. Não se pode correr o risco de acreditar que a fonte seja expressão de uma verdade descoberta, mas sim entendê-la como um registro por parte de seu autor, de suas impressões e pontos de vista.

Das cartas analisadas somam-se 12, de 37 folhas no total, do período de 1929 a $1933^{2}$. Algumas foram escritas em papel timbrado e apresentam marcas de um português 
da época. Muitas palavras estão ilegíveis ou rasuradas ${ }^{3}$. Entre os assuntos que se destacam estão os relatos acerca da viagem de Ignácia Guimarães a Europa; condições da educação e das escolas alemãs, a sua atuação enquanto educadora, questões de sua vida pessoal, profissional e a atuação de Anísio Teixeira enquanto administrador do Ensino Público na antiga Capital Federal, Rio de Janeiro.

Essa correspondência se mostra uma preciosa fonte de estudo, pois traz descrito mesmo que seja do ponto de vista da remetente Ignácia Guimarães a representação de sua atuação no campo educacional e de determinado modelo de educação valorizado naquele momento e que estava a se impor, circulando em esfera nacional e internacional.

Companheiros de classe no Teacher's College em 19284, discípulos de Dewey, Ignácia Guimarães e Anísio Teixeira fizeram parte de uma geração de educadores que viajaram a outros países com o intuito de estudarem, se especializarem e conhecerem de perto a realidade de lugares considerados como mais "civilizados", referências em matéria de educação, pois a viagem é um fator de distinção, há uma diferença entre aqueles que podem comprovar daqueles que apenas ouviram ou leram.

Conhecer in loco experiências culturais, sociais, educacionais ou políticas de um país concede ao viajante um lugar de autoridade, sendo-lhe permitido falar, escrever e comparar o visto, o ouvido e o vivido (VINÃO, 2000). Assim, no Brasil e no mundo, inúmeros viajantes viram nas viagens pedagógicas o meio de aprender com os países sobre o que estavam desenvolvendo de mais moderno em matéria de difusão, métodos e organização do ensino.

Schuller (2007) observa que a iniciativa das viagens de estudos aconteceu ainda no decorrer do século XIX, onde professores, diretores de estabelecimentos educacionais e inspetores de instrução pública percorreram países estrangeiros, participando inclusive como representantes do Império do Brasil nas celebradas Exposições Internacionais.

De acordo com a autora, em 1890 o governo provisório estabelecia os princípios gerais que informariam a reforma da instrução primária e secundária no Distrito Federal. Entre tais princípios estava a previsão de realização de viagens pedagógicas, ou seja, a designação de professores brasileiros dos vários níveis e instituições de ensino, para examinarem durante dois anos os progressos da instrução e aperfeiçoar as suas habilitações profissionais nos países estrangeiros, sobretudo na Europa e nos Estados Unidos da América.

As viagens de estudo continuam com o fim do Império e o inicio da República, pois há um empenho por parte daqueles que pensaram na modernização do país em fundação de escolas e organização de sociedades destinadas a propagar a instrução popular. Essa geração concentra seu interesse de modernização em iniciativas e inovações pedagógicas que vinham, de países estrangeiros, imprimindo um novo perfil à instrução pública brasileira (CARVALHO, 2011).

Assim, no Brasil, como também em outros países houve uma busca por operar mudanças na educação nacional, tomando como parâmetro experiências realizadas no estrangeiro. A busca por modelos mais desenvolvidos de educação parece que asseguraria um grau de legitimidade respeitável ao país que implantava determinado modelo, pondo-o de certa forma, em condições de igualdade educacional com o outro país considerado mais desenvolvido.

De acordo com Vidal (2005), entre o fim do século XIX e início do século XX, o trânsito de educadores entre os países da Europa e das Américas foi constante, além da presença significativa das referências a autores e impressos europeus, sobretudo franceses e norte-americanos nos discursos de professores e reformadores brasileiros, caracterizando 
assim, uma intensa circulação de objetos e pessoas e de modelos culturais, configurando a hipótese de uma história conectada.

\section{Nas linhas da correspondência o traçado de um percurso educacional}

Ignácia Guimarães, educadora brasileira, se deslocou a países europeus no ano de 1929 para estudar o modelo de educação europeu, em especial o alemão. Ela partiu com a intenção de observar, analisar e comparar. Não apenas leu ou ouviu, mas teve o privilégio de ver o "real". Atuando como passeurs culturels no sentido proposto por Gruzinsk $(2001)^{5}$ e protagonista na formação do campo educacional, ela pode ocupar importantes cargos públicos.

Essa educadora experimentou o papel de viajante que percorre outro mundo e conhece seus segredos. Da viagem realizada aos países estrangeiros voltou não só com uma boa dose de encantamento, mas também com projetos e sonhos de pôr em prática o que havia aprendido sobre a "educação nova", e isso ela vai "confessar" por carta ao amigo Anísio Teixeira: "Enquanto as cousas vão correndo do modo que acabo de expor, eu vou procurando assimilar com calma tudo que aprendi nos Estados Unidos e na Europa, sem perder a esperança de poder um dia experimentar algo"6.

Depois de suas viagens Ignácia Guimarães teve a oportunidade de atuar mais intensamente na área educacional, surgindo-lhe vários convites por razões do conhecimento in loco adquirido em outros países, lhe permitindo um lugar de prestígio no campo educacional.

Em Minas Gerais essa educadora atuou como Técnica do Ensino Normal e, com entusiasmo comunica ao amigo Anísio Teixeira a sua designação para o novo cargo: "Fui nomeada assistente technica do ensino normal. Não sei entretanto quaes são as minhas attribuições. Devo esperar o secretario para que determine. Enquanto isso, vou gozando um pequeno repouso"?.

Em outra carta trata do convite que recebeu da instituição Mackenzie em São Paulo e de sua retomada como professora de Metodologia na Escola Normal, situação esta que a remetente considera humilhante, já que ela tinha a autoridade e a competência de está em posições mais elevadas:

\footnotetext{
"A viagem a São Paulo fez-me bem. O Mackenzie College offereceu-me um logar no Junior College for Girls, que pretende estabelecer este ano. Não me convem sahir de Minas estes primeiros annos. Tenho aqui alguns negócios que não devo abandonar agora. Por isso, vou sujeitar-me a voltar a minha cadeira de Methodologia na E. Normal. Ficarei no mesmo nível que a "meninada" que levei aos E. Unidos, e sujeita talvez à orientação dellas no trabalho. Que importa? As minhas alumnas, farei todo o bem que puder, procurando esquecer de mim mesma, de minha humilhação. Ajuda-me a enfrentar, sem ódio, a minha nova situação o facto de que, economicamente, não preciso muito do logar no magisterio" $"$
}

Ignácia Guimarães, além da área educacional atuou em outras áreas. E para não ficar ociosa, como diz na carta escrita ao amigo Anísio Teixeira, ela ocupa um novo posto de trabalho:

"Enquanto corre o tempo, para não ficar de todo ociosa, estou trabalhando, com enthusiasmo, na campanha aqui iniciada pro-extincção 
da lepra. Veja no enveloppe um dos meios de propaganda. Já vamos adquirir um terreno para construcção do abrigo dos filhos dos leprosos enternados na colonia recem-inaugurada" .

No ano de 1932 o Diretor Geral da Instrução Pública Anísio Teixeira escreve a Ignácia Guimarães convidando-a para ministrar um curso de férias na Escola Normal da antiga Capital da República, Rio de Janeiro:

\begin{abstract}
"Snrs Professora: Realizando-se, na Escola Normal do Districto Federal, um Curso de Férias, durante o mez de fevereiro vindouro, esta Directoria se sentiria muito honrada si pudesse contar com o concurso da senhora entre os dos professores que deverão ministrar differentes lições por ocasião do mesmo. Caso lhe seja possivel acceitar esse convite, tomo a liberdade de suggerir que as lições poderão obedecer o seguinte titulo geral: "Methodo de ensino de sciencia na Escola Normal". O seu curso poderá ser dado em duas ou tres semanas do referido mes, a sua escolha e com o numero de aulas que julgar conveniente. Agradecendo a sua resposta com a brevidade possivel, por isso que desejo annunciar o Curso até 15 do corrente" 10 .
\end{abstract}

Todavia, não foi possível a Ignácia Guimarães aceitar o convite, visto que, sua mãe se encontrava enferma: "Gostaria tanto de tomar parte nos trabalhos do curso de verão, especialmente tendo vindo o convite de quem tanto estimo e a quem tanto prazer teria em servir. Minha mãe continua seriamente enferma. Não poderei sahir daqui, enquanto não estiver melhor"11.

No Rio de Janeiro essa educadora ocupou alguns cargos junto a administração educacional do ensino público, quando Anísio Teixeira era o seu diretor. Na carta que escreve ao seu amigo e chefe, trata sobre os seus trabalhos no cargo de chefia de Serviço de Programmas Escolares, sobre a sua demissão deste, a sua insatisfação de ser designada para uma outra ocupação e a recomendação para que o diretor reveja a sua posição atual e a transfira para outro cargo:

"Agradeço-lhe, mui penhorada, a boa vontade que tem sempre demonstrado para comigo, procurando aproveitar meus serviços em sua inteligente administração, desde que aqui cheguei o ano passado, a seu convite. Por confiar absolutamente no Snr., ainda ha pouco aceitava eu a chefia de Serviço de Programmas Escolares, trabalho dificilimo desde a sua natureza e dada as condições em que deveria ser feito. Dediquei-me a esse trabalho com entusiasmo, apesar de todas as dificuldades encontradas para realiza-lo, e posso apresentar provas de quanto fiz, em tão pouco tempo. Tenho terminado o programa de sciencia social para o $4^{\circ}$ anno, trabalho feito cuidadosa e conscientemente, como poderão atestar dois competentes profissionaes em matérias e cuja opinião e cujas sugestões nos foram dadas - e Dr. Delgado de Carvalho e Dr. Pedro Calmon, um projeto - o principal do $5^{\circ}$ ano, que foi julgado e criticado por Dr. P. H. Rolfs, e tecnico em agricultura mui conhecido em nosso meio, assumpto que o projecto desenvolve. Os rascunhos desses trabalhos demonstram claramente o quanto eu nelles trabalhei, não desmerecendo o esforço de minhas dedicadas auxiliares, que, segundo afirmaram, tiveram 
orientação sistematisada neste trabalho. A reforma recente da organização escolar tirou-me a chefia de Serviços de Programas. Quando fui procuralo para saber que devia fazer passar a direção do Serviço à nova chefe, ficou resolvido que se me incumbiria da orientação das atividades extraclasses. Não indaguei do cargo que me seria dado para ocupar-me de tal serviço, por confiar no Snr e, assim, jamais supor que o Snr. me oferecesse uma posição que não pudesse eu aceitar. Com, surpreza, pois, recebi a designação de professora encarregada da orientação das atividades extra-classes, sob a chefia da Seção de Programas. Não desejo desmerecer nem depreciar a competencia de minha distinta colega d. Maria Reis Campos, de quem sou amiga pessoal, mas, minha situação subalterna em sua seção é absolutamente inaceitavel. Estou convencida de que isto lhe tenha passado despercebido, quando subscreveu a designação. Por isso, venho pedir-lhe reconsiderar esse ato e, si o Snr. achar que tenho competencia para desenvolver um bom programa de atividade extra-classes, visto ter eu feito cursos relativos a esses problemas, no Teachers College, e tambem desejar prestar-lhe bons serviços, então poderá dar-me uma situação condigna, pois tem à mão "a faca e o queijo", como se diz. Si o Dr. Delgado de Carvalho tiver o espírito adeantado, liberal e progressista que eu suponho que elle tenha, agradar-me-ia trabalhar sob a sua direção. Não sei o que elle pensa de mim. Não me conhece ainda, no trabalho e acredito que as informações que poderia ter recebido de outrem não podem ser a meu favor. Deixo, porém, em suas mãos, mais esta vês, com bastante confiança"12.

O fragmento da carta nos permite compreender que Ignácia Guimarães se reconheceu como alguém de autoridade para interferir sobre o lugar e a posição que deveria ocupar, pois ela não era mais um diletante, que apenas por arranjos políticos ocuparia cargos na administração do Estado, mas sim uma especialista com capitais culturais acumulados adquiridos com as suas viagens de estudo, obtendo conhecimentos específicos de um campo.

Ignácia Guimarães ainda produziu e publicou vários artigos sobre educação nas páginas da Revista do Ensino, espaço este, privilegiado, de opinião e para a elaboração de projetos visando à renovação cultural e educacional do seu país. É possível encontrar os seguintes artigos no periódico de autoria de Ignácia: "O trabalho escolar: precisa ser distribuido pelos alumnos conforme a capacidade mental de cada um destes" (Revista do Ensino, anno I - n. 1 - 8 / março/ 1925); "Porque se reprovam tantos alumnos" (Revista do Ensino, anno I - n. 2 - 14 / abril/ 1925); "Progresso dos methodos e meios de educação no Brasil" (Revista do Ensino, anno I - n. 4 - 16 / junho/ 1925); "Os modernos systemas de educação e as clínicas escolares" (Revista do Ensino, anno II - n.13 - abril / 1926).

Como intelectual, educadora e escritora, ela procurava pôr em prática uma série de iniciativas no intuito de apresentar, fazer circular e estabelecer os princípios da Escola Nova, base da pedagogia conhecida nas escolas europeias e norte-americanas, pois, além de sua viagem à Europa, Ignácia Guimarães foi designada juntamente com um grupo de professoras (Alda Lodi, Amélia de Castro Monteiro, Benedita Valadares e Lúcia Monteiro Casasanta) de Belo Horizonte, pelo secretário da Educação Pública Francisco Campos, a irem aos Estados Unidos para se especializarem na Universidade de Colúmbia, durante os anos de 1927 a 1929. O Secretário determinou as professoras que não adquirissem somente diplomas, mas sim conhecimentos. 
Assim "coube a elas a incumbência de se especializarem nas diferentes metodologias e trazer como bagagem as inovações metodológicas de acordo com os princípios escolanovistas propagados na Universidade de Colúmbia" (Maciel, 2012, p. 7). Esse grupo de professoras que foram discípulas de Dewey no "Teacher's College" formaria o núcleo inicial do corpo docente da Escola de Aperfeiçoamento mineira.

Foi no âmbito de suas viagens que Ignácia Gimarães efetuou trocas culturais e intelectuais, promovendo, segundo Vidal (2006, p. 53) "as passagens de uma cultura a outra de modelos e objetos, permitindo uma mestiçagem cultural que atravessava as fronteiras nacionais".

\section{Narrativas das condições dos países europeus e da educação alemã}

Para analisar o sentido da viagem pedagógica de Ignácia Guimarães, primeiramente tratarei do roteiro realizado por ela, ou seja, as cidades e os países visitados. Em seguida tratarei das impressões construídas pela viajante sobre a educação escolar, sobretudo a educação alemã, que terá destaque na sua narrativa.

A narrativa construída pela viajante nas suas cartas, das características dos países europeus e do modelo educacional alemão visava mais do que constituir um retrato "fiel" da realidade observada, produzir efeitos de comparação. Servindo assim, não somente para apontar as distâncias, aproximidades, semelhanças e discrepâncias entre os países e cidades, mas também para uma análise de compreensão de sentidos.

A missão de Ignácia Guimarães em países alheios era buscar os códigos de civilização, aprender de sua cultura, educação, progresso, observar, refletir, e, portanto, a comparação seria inevitável. $\mathrm{O}$ ato de comparar é uma ideia bastante antiga. A comparação é uma das maneiras de qualificar, desqualificar, condenar, avaliar, etc. Ao comparar diferentes realidades, Ignácia Guimarães deixa bem marcado o seu ponto de vista: critica, elogia, defende, condena. Deixa registrado o seu incômodo em relação a muitas questões sobre os países visitados.

O que cada um observa e registra é resultado da maneira, do lugar e do momento situacional em que se escolhe ver. Nesse olhar, muitas vezes estão embutidos crenças culturais, religiosas, costumes, hábitos, formas de ser, de agir e sentir, tensões, opiniões, desejos e sentimentos.

O olhar não é linear, tem muitas direções, curvas e obstáculos. Além de que, cada um tem a sua própria forma de ver as coisas e o seu ponto de vista, como tal, não conseguimos obter uma análise integrada da realidade, apenas uma realidade inteligível. E as interpretações de uma determinada coisa podem e são as mais diversificadas possíveis. A realidade é móvel e sua percepção depende da visão de quem a lê/vê.

O olhar jamais é neutro, ele avalia e atribui julgamentos de valores que são, ao mesmo tempo, verdadeiros e falsos. Assim é possível dizer que elementos ficcionais e reais estavam presentes nas cartas de Ignácia Guimarães. O que a viajante registrou e escreveu não é uma verdade incontestável, uma autenticidade dos fatos, mas sim uma versão, fragmentos da realidade.

Em 23/07/1929 Ignácia Guimarães escreve de GelsenKirchen, uma cidade alemã, ao amigo Anísio Teixeira, tratando do seu roteiro de viagem. A Alemanha foi o país que a viajante mais circulou, visitando as suas várias cidades.

"Já visitei as seguintes cidades neste paiz: Bremen, Hamburgo, Hasburgo, Lübeste, Berlim, Patodam, Halle, Madgsburg, Weimar, Jena, Leipzig, Dresden, München, Mürnberg, Heidelberg, Frankfurt, Mainz, Wüsbaden, 
Bonn, Köln, Dusserdolf, Barmen, Essen e esta cidade. Visitaremos duas mais e teremos terminado esta interessantissima viagem" $"$.

A Alemanha e as suas cidades são apresentadas de forma positiva, a viajante demonstra todo o seu encantamento, alegria e satisfação pela sua excursão, pelo país e pelo povo alemão, com quem fez muito bons amigos, homens e mulheres. A Alemanha aparece como um país interessante sob vários aspectos:

"Tenho passado um "Summer" agradabilissimo: a excursão pela Allemanha foi excelente sob vários pontos de vista. O grupo era muito sympathico, os leaders mui competente e o programma optimo. Visitamos cerca de 24 cidades e tivemos ensejo de conhecer o paiz sob varios aspectos. Deixei a Allemanha encantada pelo povo e pela terra e presumo que lá deixei alguns amigos (de ambos os sexos), cuja amizade vae ser de grande proveito para mim, pois são educadores conceituadissimos no paiz" 14 .

"Quis conhecer algo da Suissa allemã. Passei dois dias em Zurick. Não calcule quanto apreciei aquella cidade! Parece que tudo alli transpira hygiene, saude, arte, prosperidade e plena vida. As casas muito bem cuidadas, as ruas limpissimas, o povo bem trajado e com apparencia de gente muito feliz!" 15 .

A remetente compara a cidade alemã Zurick com Viena, demonstrando o grande abismo e contraste social existente. Na sua escrita comparativa, ela demonstra surpresa de realidades sociopolíticas tão diferentes:

"De Zurick vim a Vienna. Que contraste! Nunca vi tanta pobreza! Não lhe descrevo a cidade porque presumo que o Snr. a conhece. Não quis conhecer em Vienna o que alli se encontra de histórico, dediquei grande parte do meu tempo ao estudo do interessantissimo programma de serviço social que vem sendo executado pelos representantes do partido socialista. Como o Snr. sabe, ha alli dois fortes partidos politicos - um socialista radical e outro socialista christão. Ha, além destes dois partidos, um pequeno grupo - pan-germanico. Os dois partidos têm estado em lucta constante, porém, depois do movimento mais violento em 1927, o socialista radical teve de ceder muitos dos postos a seu opponente, de sorte que seu programma tem sido um tanto prejudicado" $"$.

No relato de Ignácia Guimarães é possível observar que o planejamento prévio de sua circulação se altera. Estava programada para viajar a certos países, todavia, motivos mais fortes, razoáveis e concebíveis a fazem mudar de ideia e altera o seu roteiro:

"Não fui a Dinamarca conforme planejava porque informaram-me ser o programma da conferencia alli mui semelhante ao de Genève. Em vez de ir até lá, resolvi conhecer quatro paizes, além da Alemanha e Suissa. São estes: Austria, França, Belgica e Hollanda. (?) os motivos mais fortes para esta resolução foi o facto de ter conhecido uma senhora durante a viagem pela Allemanha, que conhece este continente a palmo e que ia fazer uma viagem por aquelles paizes. Tive a felicidade de inspirar-lhe 
sympathia e confiança. Ella insistiu para que eu viajasse com Ella. Acceitei seu comvite e ainda não me arrependi: Ella conhece mil e um meios de viajar o mais possivel, com segurança e conforto e pelo minimo custo. Esta senhora é americana e professora de allemão e francez numa das high schools for (?) de Boston. Ella fazia parte do grupo com que viajei na Allemanha" 17 .

Durante o seu percurso pelos países europeus, a viajante Ignácia Guimarães observa, explora e analisa as cidades. Encanta-se com alguns aspectos, monumentos e paisagens e acredita ser desinteressante outros. Ela é uma observadora que apreende cada detalhe que vê. Busca uma nova percepção dos lugares por onde passa, procurando compreender as suas características, pormenores, singularidades, semelhanças e particularidades. E com entusiasmo relata por carta ao amigo Anísio Teixeira as suas visitas realizadas:

\begin{abstract}
"Hoje passámos o dia nesta velha e legendaria cidade da Austria. Hontem estivemos em Melk, onde se encontra um dos mosteiros mais famosos da Europa. Foi fundado em 1089 e possue uma das famosas bibliotecas benedictinas. Contem 80.000 volumes, alguns dos quais de grande valor histórico. De Melk a Vienna fomos hontem pelo lendário Danubio que não tem o mesmo encanto que o Rheno, porém é bastante interessante. Paramos em Düretein para visitas as ruinas de seu castelo que é das mais pitorescas da região. Alli esteve preso Ricardo o Coração de Leão, quando voltava da Terra Santa" ${ }^{\prime 18}$.
\end{abstract}

Além de relatar nas cartas o seu roteiro cultural, Ignácia Guimarães também relata o seu roteiro pedagógico (visita as escolas, a museus, edifícios e sítios históricos, leitura dos programas escolares):

"Tenho pensado em escrever-lhe muitas vezes, porém, de facto, só hoje o
faço porque meu tempo tem sido completamente tomado pelo programma
de visitas a escolas, museus, edificios e sitios historicos, banquetes,
recepção, etc. etc. Para que o Snr. faça uma idea da vida que o nosso
grupo aqui tem levado, eu envio um exemplar do programma para (?) que
é, relativamente, um dos mais suaves que nos tem sido offerecido"19.

A viajante também conta ao amigo a sua participação nas conferências, pois o objetivo de sua viagem, além de conhecer os sistemas educacionais era também obter informação, renovar a aprendizagem, descobrir e aprender com outros países, outros povos sobre o que estavam discutindo em relação ao tema educacional, e, como educadora e uma viajante ávida por aprender, renovar seu conhecimento no campo que atuava, procura conhecer as novidades de uma educação diferenciada:

"No dia vinte e cinco deste, sigo em companhia de quatro membros do grupo para Genève onde assistirei ao meeting da World Education Federation. No fim de duas semanas partirei para Dinamarca e em (?) assistirei a conferencia da (?) Education (?) que durará cerca de duas semanas também"20. 
"Estive na Suissa durante uma semana. Em Genève assisti ao meeting da W. Federation of Educ. Association. Lá encotrei muitos conhecidos de Columbia e aprendi muito sobre o que se vem fazendo no mundo em matéria de educação, saude, trabalho social, etc." ${ }^{21}$.

Em sua viagem Ignácia Guimarães procurou buscar elementos positivos de informação, pois esta viagem era formadora, educadora, no sentido em que se aprende com os contatos e conhecimentos novos.

Outro assunto foi destaque e razão para que a viajante escrevesse ao amigo Anísio Teixeira - as características da educação e escolas alemãs. A narrativa de Ignácia Guimarães opera no sentido de selecionar de dar visibilidade a esse modelo educacional, realizando assim, um exercício comparativo.

De acordo com Ferreira (2009) a comparação em educação gera uma dinâmica de raciocínio que obriga a identificar semelhanças e diferenças entre dois ou mais fatos, fenômenos ou processos educativos e a interpretá-las levando em consideração a relação destes com o contexto social, político, econômico, cultural, etc. a que pertencem.

O autor diz ainda não haver dúvida de que é na comparação dos fenômenos, fatos e processos relativos à Educação em diferentes contextos que a educação comparada toma seu sentido. Na maior parte das vezes ela tem assumido dimensão internacional, mas pode também assumir uma nacional, regional ou supranacional.

Isso é possível compreender quando Ignácia Guimarães compara o "outro" com o já conhecido, aquilo que faz parte de seu mundo social e cultural. Está numa posição privilegiada, é uma educadora, participa das questões educacionais de seu Estado, Minas Gerais, e do seu país, o Brasil. E ainda, viajou aos Estados Unidos e a vários países da Europa, conheceu algumas instituições educacionais, o que lhe concede o poder de analisar e comparar uma realidade com outra.

Ignácia Guimarães é uma inquiridora, ou seja, uma observadora, no sentido proposto por Noah e Eckstein (FERREIRA, 2009). Os inquiridores22 durante boa parte do século XIX deslocavam-se a outros países no intuito de recolherem e importarem aspectos referentes a métodos, programas e organização de ensino que pudessem servir para melhorar o sistema educativo de seus países.

A viajante por meio de suas cartas vai apresentar, relatar, descrever o que presenciou e as suas opiniões, posições e sensações em relação a educação alemã. Ela partilha a sua experiência com alguém que é do campo, um intelectual e reformador empenhado na reforma da sociedade por meio da educação.

Ignácia Guimarães busca compreender as características e o funcionamento das instituições educacionais alemãs observadas. O relato que faz se organiza de modo a tornar visíveis os seus pontos positivos. No seu relato comparativo, apresenta o projeto de educação alemão como referencial, servindo de modelo para outros.

Em carta escrita em 23/07/1929, Ignácia Guimarães lamenta não dispor de tempo suficiente para relatar ao amigo Anísio Teixeira o interessante sistema educacional alemão, todavia não deixa de registrar o seu entusiasmo e surpresa pelo grande esforço do povo alemão no investimento da educação das novas gerações:

"Sinto não dispôr de tempo sufficiente para contar-lhe algo do que tenho visto e observado de interessante. Já vi mais de uma centena de escolas e a minha impressão é a melhor possível. É admiravel o esforço e o sacrificio que o povo allemão está fazendo com o fim de preparar 
efficientemente a nova geração para enfrentar a responsabilidade que o passado $^{23}$ collocou sobre seus hombros" 24 .

Das suas visitas às escolas alemãs, Ignácia Guimarães teve a oportunidade de entrar em contato com um modelo educacional considerado por ela como modelar. Conheceu diferentes tipos de escolas que desenvolviam trabalhos interessantes:

"Os gymnasios, as escolas profissionaes e os seminários para os
professores assim como as "community schools" são os tipos de escolas
que mais tem me agradado visitar porque estes estabelecimentos são os
melhores que eu tenho visto até hoje. Em todas as cidades temos ouvido
longas exposições da septima da educação allemã. Si, como diz
Thorndike, "prostiu makes perfict", devo esperar conhecer a septma,
quando terminar a viagem" 25 .

Com entusiasmo Ignácia Guimarães trata dos esforços, da garra e da fé da Alemanha em promover condições e elementos necessários e positivos para que se possa desenvolver fisicamente e moralmente a juventude escolar alemã.

"Escolas ao ar livre, campos de férias e de jogos, excursões, fornecimento de alimentação e de tudo mais que possa fazer da juventude uma gente physica e moralmente forte - a Allemanha está promovendo com um afam e com uma fé invejaveis" 26 .

Além da educação, os professores alemães deixaram boas impressões na viajante Ignácia Guimarães. Ela observa ter "apreciado immensamente os educadores allemães, dentre os quais tenho já a ventura de contar bons amigos ${ }^{27}$. Parece-me que os conheço ha annos, tal a bondade e o interesse em que tenho sido tratada aqui" 28 . A remetente acredita que o tratamento amável que tem recebido dos professores alemães se devem "as bondosas referencias que o Dr. Alexander e Dr. Hilker (um dos leaders da educação neste paiz e com quem estudei em Columbia, no ano de 1928) tem feito a minha modestissima pessoa".

Tais são a admirações de Ignácia Guimarães aos professores alemães, que segundo ela "não medem sacrificios para realizar o programma de revigoramento da nação" 29 a fim de promover uma educação eficiente.

Os professores alemães também realizavam atividades em conjunto com os pais, no intuito de estreitarem laços, comunicação e fazer com que os pais fossem agentes auxiliares de uma educação inovadora: "tivemos a felicidade de poder presenciar a execução do trabalho em conjunto que os pais e mestres estão realizando afim de fazer da escola uma fonte de energia e verdadeira educação prática" ${ }^{\text {"30 }}$.

Observamos assim, que as cartas escritas por Ignácia Guimarães traz a representação de um modelo educacional "ideal", apresentando um projeto modelar e diferencial de escolas, atendendo as necessidades de alunos e professores; oferecendo condições e elementos que estimulem a aprendizagem dos alunos alemães; abrindo as suas portas para que novos atores sociais possam adentrar, como a participação dos pais em trabalho conjunto com os docentes.

Outra condição que favorece o desenvolvimento da educação alemã são os esforços e garra dos professores para cumprir o programa, o currículo escolar. Assim, o 
sacrifício dos mestres seria compensado na ajuda por uma educação eficiente e o crescimento da nação.

O modelo escolar representado nas cartas de Ignácia Guimarães, aclamado como instituição modelar e especializada para atender novas demandas provocadas pelas transformações sociais (BUENDÍA, 2000), nasceu e se consolidou no mundo europeu e "adquiriu "características universais", impondo-se como fator decisivo das regulações culturais e econômicas presentes na cena internacional" (HOUSSAYE, 2007, pg. 302). Atravessou fronteiras na criação, expansão e consolidação dos sistemas públicos de ensino, num processo de difusão mundial e de uma cultura escolar histórica e socialmente construída (JULIA, 2001).

Dessa forma, a narrativa pedagógica apresentada/representada nas cartas de Ignácia Guimarães enviadas ao amigo Anísio Teixeira caracteriza-se pela valorização desse novo paradigma - de uma nova pedagogia, de um modelo escolar diferenciado, de professores e alunos.

\section{Referência}

BUENDÍA, Miguel. Modelos de escola na história de Moçambique. In: NÓVOA, António e SCHRIEWER, Jürgen (Eds.). A difusão mundial da escola. Lisboa: Educa, 2000. p. 151-155.

CARVALHO, Marta Maria Chagas. Pedagogia Moderna, Pedagogia da Escola Nova e Modelo Escolar Paulista. In: CARVALHO, Marta Maria Chagas de e PINTASSILGO, Joaquim (orgs.). Modelos Culturais, Saberes Pedagógicos, Instituições Educacionais: Portugal e Brasil, Histórias Conectadas. São Paulo: EDUSP/FAPESP, 2011, p. 185-212.

FERREIRA, António Gomes. O sentido da educação comparada: uma compreensão sobre a construção de uma identidade. In: SOUZA, Donaldo Bello de e MARTíNEZ, Silvia Alicia (orgs). Educação comparada: rotas de além-mar. São Paulo: Xamã, 2009, p. 137166.

GOMES, Angela de Castro. Escrita de si, escrita da História: a título de prólogo. In: GOMES, Angela de Castro (org). Escrita de si, Escrita da História. Rio de Janeiro: FGV, 2004.

GRUZINSKI, Serge. O pensamento mestiço. São Paulo: Companhia das Letras, 2001.

GUIMARÃES, Ignácia. O trabalho escolar: precisa ser distribuido pelos alumnos conforme a capacidade mental de cada um destes. Revista do Ensino, ano I, n. 1, março, 1925 , p. 4.

GUIMARÃES, Ignácia. Porque se reprovam tantos alumnos. Revista do Ensino, ano I, n. 2, abril, 1925, p. 42-43.

GUIMARÃES, Ignácia. Progresso dos methodos e meios de educação no Brasil. Revista do Ensino, ano I, n. 4, junho, 1925, p. 87. 
GUIMARÃES, Ignácia. Os modernos systemas de educação e as clínicas escolares. Revista do Ensino, ano II, n.13, abril, 1926, p. 108-110.

HOUSSAYE, Jean. Pedagogias: importação-exportação. In: Viagens pedagógicas. MIGNOT, Ana Chrystina Venâncio e GONDRA, José Gonçalves (orgs). São Paulo: Cortez, 2007, p. 294-314.

JULIA, Dominique. A Cultura Escolar como Objeto Histórico. Revista Brasileira de História da Educação. n. 1, jan./jun., 2001, p. 9-43.

MACIEL, Francisca. Alfabetização em Minas Gerais: adesão e resistência ao método global - parte 1. Texto em pdf, p. 1 a 10. Acesso em 23/07/2012. http://crv.educacao.mg.gov.br/SISTEMA_CRV/index.aspx?\&ID_OBJETO=29831\&tip

MIGNOT, Ana Chrystina Venancio. Papéis guardados. Rio de Janeiro: UERJ/Rede Sirius, 2003.

SCHUELER, Alessandra Frota M. A longa peregrinação de um professor da roça na Europa. In: In: Viagens pedagógicas. MIGNOT, Ana Chrystina Venâncio e GONDRA, José (orgs). São Paulo: Cortez, 2007, p. 90-113.

VIDAL, Diana Gonçalves. Culturas Escolares: estudo sobre práticas de leitura e escrita na escola pública primária (Brasil e França, final do século XIX). Campinas, SP: Autores Associados, 2005.

VIDAL, Diana Gonçalves. Fronteiras e Mestiçagens Culturais: A circulação de objectos, pessoas e modelos pedagógicos como problemática em história da educação (Brasil, EUA, França e Portugal no final do século XIX). Estudos do Século XX, nº 6, 2006, p. 43-55.

VIÑAO, Antonio. Las autobiografias, memorias y diários como fuente histórico-educativa: tipologia y usos. Revista Teias, UERJ, Rio de Janeiro, volume 1, 2000, pgs 82- 95.

Notas

1 Doutoranda em educação pela Universidade de São Paulo (USP). Bolsista FAPESP e-mail: sfcardoso2011@hotmail.com

${ }^{2}$ As cartas estão localizada no arquivo pessoal de Anísio Teixeira sob a guarda do CPDOC - Centro de Pesquisa e Documentação de História Contemporânea da Fundação Getúlio Vargas no Rio de Janeiro.

${ }^{3}$ Quando não for possível a leitura, tradução de uma determinada palavra virá entre parênteses um ponto de interrogação, indicando a impossibilidade da compreensão da palavra.

${ }^{4} \mathrm{Na}$ carta datada de 09/08/1929 enviada a Anísio Teixeira, Inácia Guimarães relembra suas vidas de estudantes no Teacher's College na Universidade de Columbia: "Espero vel-o na Bahia muito breve. Oxala o Snr. Director Geral da Instrucção Pública do Estado da Bahia possa deixar o cargo e o longuíssimo titulo por alguns instantes e vir palestrar um pouco a bordo commigo. A fim de revivermos, como simples ex - T. College students, "os dias new-yorkinos -" "de saudosa memória"”.

${ }^{5}$ Os passeurs culturels são elementos, que podem ser pessoas, objetos, símbolos, os quais atuam como mediadores entre tempos e espaços diversos, contribuindo na circulação de representações e modelos, no 
entrecruzamento de variados universos culturais (Gruzinski, 2001). Apud SCHUELER, Alessandra Frota M. A longa peregrinação de um professor da roça na Europa. In: In: Viagens pedagógicas. MIGNOT, Ana Chrystina Venâncio e GONDRA, José (orgs). São Paulo: Cortez, 2007, nota de rodapé nº 2, p. 91.

${ }^{6}$ Carta escrita em 24/10/1929. Arquivo Anísio Teixera, CPDOC/FGV.

${ }^{7}$ Carta escrita em 26/09/1929. Arquivo Anísio Teixera, CPDOC/FGV.

${ }^{8}$ Carta escrita em 07/02/1931. Arquivo Anísio Teixera, CPDOC/FGV.

${ }^{9}$ Carta escrita em 01/02/1932. Arquivo Anísio Teixera, CPDOC/FGV.

${ }^{10}$ Carta escrita em 09/01/1932. Arquivo Anísio Teixera, CPDOC/FGV.

${ }^{11}$ Carta escrita em 01/02/1932. Arquivo Anísio Teixera, CPDOC/FGV.

${ }^{12}$ Carta escrita em 21/09/1933. Arquivo Anísio Teixera, CPDOC/FGV.

${ }^{13}$ Carta escrita em 23/07/1929. Arquivo Anísio Teixera, CPDOC/FGV.

${ }^{14}$ Carta escrita em 09/08/1929. Arquivo Anísio Teixera, CPDOC/FGV.

15 Idem.

${ }^{16}$ Ibiden.

${ }^{17}$ Ibiden.

${ }^{18}$ Ibiden.

${ }^{19}$ Carta escrita em 23/07/1929. Arquivo Anísio Teixera, CPDOC/FGV. Grifos da autora da carta.

${ }^{20}$ Idem.

${ }^{21}$ Carta escrita em 09/08/1929. Arquivo Anísio Teixera, CPDOC/FGV.

${ }^{22}$ Grifo do autor Ferreira (2009).

${ }^{23}$ Grifos da autora da carta.

${ }^{24}$ Carta escrita em 23/07/1929. Arquivo Anísio Teixera, CPDOC/FGV.

${ }^{25}$ Idem.

${ }^{26}$ Ibidem.

${ }^{27}$ Grifos da autora da carta.

${ }^{28}$ Ibidem.

${ }^{29}$ Ibidem.

${ }^{30}$ Ibidem.

Recebido: abril-13 Aprovado: novembro-13 